\title{
ESTUDIOS SOBRE MIGRACIONES MEDITERRÁNEAS DEL SIGLO XVI AL XX: VILAR, BONMATÍ, BONO, BENNASSAR, LÓPEZ NADAL, LUCCHINI
}

Por

MÍKEL DE EPALZA

Un conjunto de nuevos e importantes estudios van mejorando el conocimiento de las emigraciones, de índole diverso, que vieron las aguas del Mediterráneo en época moderna y contemporánea. Las causas de esta abundante y cada vez más cualificada producción investigadora se reducen en cierta manera a dos: curiosidad en mostrar los «pasos» que se dieron en el pasado entre Europa y el Mundo Islámico mediterráneos, a pesar de las divergencias religiosas y culturales aparentemente irreconciliables, y la relativa abundancia de la documentación, conservada especialmente en los archivos europeos. Exotismo del tema y especificidad de la documentación serían los principales alicientes de este campo de investigación euro-árabe.

El libro de Juan Bautista VILAR, Los españoles en la Argelia francesa (1830-1914) (con prólogo de José María Jover Zamora, editado por el Centro de Estudios Históricos, del C.S.I.C., y por la Universidad de Murcia, 1989, 436 pp.), reasume de forma notablemente ampliada la ingente documentación recogida ya en su precedente Emigración española a Argelia (1830-1900). Colonización hispánica de la Argelia francesa (Madrid, 1975), que era un clásico en la materia.

El libro de Vilar es un libro de historia, pero es también un profundo libro de sociología de las emigraciones de españoles a la Argelia ocupada por los franceses a partir de 1830. El marco político, en ambas riberas del Mediterráneo, acompaña y explica el ritmo y las modalidades de esa importante corrientes de españoles, al socaire de la colonización francesa en esas tierras árabes. Son sobre todo las condiciones socioeconómicas del pais de origen (España de mediados del siglo XIX) y del de inserción las que explican las formas de emigración, temporales o definitivas. Vilar da también un tratamiento especial a las condiciones jurídicas de los españoles en la colonia francesa. Los grupos minoritarios de emigrantes que se distinguen de 
la masa de los emigrantes laborales (políticos, eclesiásticos, diplomáticos...) le merecen un tratamiento especial.

El libro del Catedrático de Historia Contemporánea de la Universidad de Murcia, Juan Bta. Vilar Ramírez, se caracteriza por su sólida erudición, avalada por la abundante documentación y exhaustiva bibliografía. Pero se recomienda también por su estilo: es conciso, pero muy matizado, ameno por las muchas noticias concretas aunque nunca baladies. Se distingue, en efecto, por la profundidad y matización de sus juicios, que abren amplísimas perspectivas sobre toda una época, la del colonialismo europeo en el Mágreb árabe. Es significativo el poco espacio que ocupa en este libro la población árabe de Argelia: su poco peso no es más que el reflejo de la marginación a la que se vieron relegados los argelinos por las estructuras de la Argelia colonial francesa, en la que se integró la emigración española. Es de esperar que el libro de Juan Bautista Vilar, que se acaba con el inicio de la Primera Guerra Mundial de 1914, se vea pronto completado con un segundo volumen sobre la emigración española a Argelia hasta la Independencia argelina de 1962, especialment alrededor de la Guerra Civil Española y la Primera Guerra Mundial, así como sobre el reflujo de españoles y descendientes más o menos lejanos de españoles, tras esa independencia nacional de Argelia.

El libro de José Fermín BONMATÍ ANTÓN, La emigración alicantina a Argelia (siglo XIX y primer tercio del siglo XX) (Alicante, Universidad de Alicante y Caja de Ahorros Provincial de Alicante, 1989, 270 pp.), intenta especificar el tema de la emigración española a Argelia estudiando la de la provincia de Alicante, que nace precisamente con el segundo tercio del siglo XIX. No es tan ambicioso, pero sigue la misma línea del de Vilar, con una documentación complementaria. Trabajo académico, en el marco de las actividades del área de Geografía Humana de la Universidad de Alicante, se interesa especialmente por el origen local y la procedencia sociológica de la emigración alicantina a la Argelia colonial.

El libro de Salvatore BONO, Siciliani nel Maghreb (Mazara del Vallo, Liceo Ginnasio «Gian Giacomo Adria», 1989, 155 pp.), también es el resultado de las muchas investigaciones del profesor de la Universidad de Perugia, pero toma la forma de unas biografias, siete. Tras dos capítulos generales, para explicar el marco de esas emigraciones de sicilianos en el Mágreb árabe, emprende la presentación de esos biografiados, adoptando el estricto método de historiador documentado, sin más concesión a la creación literaria que la ordenación del material y las reflexiones que sitúan a los personajes en sus respectivas épocas y ambiente social: el obispo de Catania Nicola Maria Caracciolo, esclavo en Trípoli, capturado en el mar en 1561 y rescatado diez meses después, que escribe sobre la situación de la ciudad gobernada por Dragut; el poeta Antonio Veneziano, cautivo en Argel en 1578 y compañero de Cervantes; fray Alipio de Palermo, preso por los tripolinos en 1643, en situación eclesiástica irregular entre los cristianos de Trípoli, convertido al Islam, arrepentido y finalmente mártir de su fe cristiana tras haber insultado públicamente a la religión islámica, en 1645; el marqués de San Giuliano, que huía por haber asesinado a dos mujeres y fue capturado también por tripolinos en 1783, haciéndose pronto musulmán y obteniendo cargos en la Regencia; el avariento príncipe de Paternó, cautivo en Túnez en 1797; el médico Sebastiano Zaccaria, que emigró a Trípoli en 1902, para ejercer su oficio, pero que se vio implicado en los acontecimientos que prece- 
dieron a la ocupación italiana de Libia en 1911; y finalmente el ingeniero Francisco Bono, abuelo del autor de este libro, que impulsó la agricultura en la colonia italiana y se interesó apasionadamente por la historia y las tradiciones libias, afición que ciertamente ha desarrollado científicamente el profesor Salvatore Bono, el mejor especialista italiano actual sobre Libia y sobre las relaciones italo-magrebíes. El libro es de ágil lectura y abre nuevas perspectivas sobre las variadas situaciones de los emigrantes italianos en el Mágreb, entre el XVI y el XVIIl.

El libro del matrimonio Bartolomé y Lucile BENNASSAR, Los cristianos de Allah (la fascinante aventura de los renegados) (Madrid, Nerea, 1989. Edición francesa Les Chrétiens d'Allah. L'histoire extraordinaire des renégats. XVle-XVIle siècles, París, Perrin, 1989,493 pp.), es una obra maestra en el tema y en la gran trayectoria de historiador del hispanista francés. A partir de una abundante documentación, especialmente de los tribunales de la Inquisición, analizan la situación de los llamados «renegados» del cristianismo, los «islamizados» convertidos al Islam, con su multiforme pero importante estatuto socio-religioso, a caballo entre las dos sociedades, la europea de origen y la islámica de adopción.

A pesar de la parcialidad reconocida de su documentación original, el libro de Bennassar la somete a diversos tratamientos metodológicos para exprimir toda la información posible, que expone en dos líneas convergentes: la de biografías de personajes concretos y la de situaciones sociológicas riquísimas en enseñanzas sobre los intercambios y emigraciones entre el mundo europeo y el mundo islámico. Una tercera parte sabe superar la abundancia de datos personales y sociológicos para analizar «el sueño turco y la nostalgia cristiana», como motores o contexto de las inmigraciones de europeos al mundo musulmán.

Este libro es realmente una obra de arte histórica, no sólo por el interés del tema y la riqueza de la documentación, sino también por el estilo narrativo de la presentación. Aunque es un profundo tratado sobre esos emigrantes que cambiaron de estatuto religioso por imperativos sociales, hace viajar también al lector, de una parte a otra del Mediterráneo, precisamente en esos siglos en que parece que la frontera ideológica y religiosa había creado un espacio particularmente agresivo. No todo es agresividad en esas relaciones entre cristianos «al servicio del Allah de los musulmanes» y sus tierras y familias de origen. Y los horrores agresivos de la historia se equilibran con el estudio minucioso y respetuoso de las motivaciones, magistralmente expuestos por los profesores de Toulouse.

Más limitada en el tiempo y el espacio, pero con la erudición exhaustiva de una tesis doctoral, la obra de Gonçal LÓPEZ NADAL, El corsarisme mallorquí a la Mediterrània occidental 1652-1698: un comerç forçat (Palma de Mallorca, Conselleria d'Educació i de Cultura del Govern Balear, 1986, 623 pp.), analiza el contexto económico en el que se realizaban emigraciones de comerciantes, marinos, militares y prisioneros entre los diversos países del Mediterráneo, incluidos los magrebies, a partir de la isla de Mallorca. El valor de esta magistral tesis es múltiple, pero puede centrarse en las múltiples direcciones en las que se desarrolla la actividad económica de esos inmigrantes especiales del Mediterráneo. Nuevos estudios que el profesor de la Universidad Balear promete sobre la estructura social isleña que permite el corso traerán aún nuevas luces sobre la complejidad socioeconómica, pero también ideo- 
lógica, que justifica la depredación del corso, como institución mediterránea, tanto en países musulmanes como en países europeos.

Finalmente, de estos valiosos libros que aquí se presentan, el libro de Enrica LIC$\mathrm{CHINI,} \mathrm{La} \mathrm{merce} \mathrm{umana.} \mathrm{Schiavitù} \mathrm{e} \mathrm{riscatto} \mathrm{dei} \mathrm{liguri} \mathrm{nel} \mathrm{seicento} \mathrm{(Roma,} \mathrm{Bonacci}$ editore, 1990, 225 pp.), analiza la estructura de la esclavitud a través de la comunicación que proporciona la institución del «Magistrato per il Riscatto degli Schiavi», instituida en Génova en 1597. El profesor Salvatore Bono, en su prólogo a este libro, hace notar el interés de esta investigación y la importancia de la documentación de que dispone. La investigación plantea toda la estructura de la redención de los cautivos, desde la prueba burocrática del origen cristiano del esclavo, el financiamiento del rescate, los intercambios, los pagos y la vuelta. Particular interés para el arabista tiene el capitulo sobre los esclavos magrebies en la Liguria y las informaciones que el magistrado obtenía del obligatorio interrogatorio al que era sometido el esclavo rescatado, sobre las condiciones de vida y el mercado de los esclavos en las diversas plazas del Norte de África. Se trata, en efecto, de otro camino de emigración entre los dos «bloques» políticos del Mediterráneo.

La presentación, pues, de estos seis libros sobre emigraciones en el Mediterráneo, en época moderna y mediterránea, con marcos sociológicos diferentes, no puede ser más que positiva y elogiosa, porque se trata de obras maduras, con documentación inédita, que trata de los temas con un rigor metodológico universitario. Se han escogido precisamente por su seriedad, de entre muchos otros estudios que tratan actualmente de estos temas. No podemos calificar de serio el libro de Jacques Jordi sobre los españoles en Orán, que apenas utiliza más documentación que la que saca del libro de Juan Bta. Vilar (al que menciona, evidentemente) y que pretende un éxito de lectores en francés, entre los emigrantes de Argelia, tras la independencia argelina. Sólo se puede mencionar como libro de divulgación.

Estos trabajos invitan también a una reflexión sobre emigraciones actuales en el Mediterráneo. Las más estudiadas han sido evidentemente las emigraciones laborales de magrebies hacia Europa. Constituyen una masa de población muy importante, destinada a serlo cada vez más, hasta en ciertas regiones españolas. Pero hay una emigración más temporal pero muy cualificada, entre los diversos países del Mediterráneo: la de técnicos, políticos, turistas, comerciantes, transportistas por mar y aire, etc. La rapidez y libertad con la que circulan forma un evidente contraste con las emigraciones del pasado y muestran que la historia, con sus constantes geográficas y humanas, tiene sus variantes de épocas y lugares. 